\section{Auto-imagem corporal de adolescentes atendidos em um programa multidisciplinar de assistência ao adolescente obeso}

\section{Adolescent's self-image in a muldisciplinary program assisting obese adolescents}

\author{
Maria das Graças C. Ferriani 1 \\ Taísa Silva Dias 2 \\ Karine Zendonadi da Silva 3 \\ Camilla Soccio Martins 4
}

\begin{abstract}
This study had the objective of acquiring knowledge of obese adolescents'perception related to their bodies when placed before a mirror and the impact of such perception in their social life. We used a qualitative approach; data were collected through semi-structured interviews. Data collection was focused on 14 obese adolescents aged between 10 and 13 years old who participated of the "Multidisciplinary Assistance Program for Obese Adolescents" in the year of 2002. Data analysis consisted in disclosing adolescents statements, with two nuclei being identified: "The relationship between the obese body and the mirror", "The influence in social life". We concluded that obese adolescents had conflicting feelings related to their bodies with an unmistakable fear of looking at themselves on the mirror due to body dissatisfaction and rejection; in addition they experienced stigmatizing facts which reflected negatively in their social relations.
\end{abstract}

Key words Obesity, Teen health, Self concept
Resumo O presente estudo teve como objetivo conhecer a percepção de adolescentes obesos em relação ao seu corpo quando dispostos diante de um espelho e a sua influência na sua vida social. Foi utilizada a abordagem qualitativa; os dados foram coletados através de entrevistas semi-estruturadas. A coleta de dados ocorreu com 14 adolescentes obesos de ambos os sexos, na faixa etária entre 10 a 13 anos, e que participaram do "Programa Multidisciplinar de Assistência ao Adolescente Obeso" no ano de 2002. A análise dos dados constituiu-se em descobrir os núcleos temáticos contidos nas falas dos adolescentes, identificando-se dois núcleos: "A relação entre o corpo obeso e o espelho"; "As influências na vida social". Concluiu-se que os adolescentes obesos apresentaram sentimentos conflituosos com relação ao seu corpo, manifestando o receio explícito de se olharem no espelho, devido à insatisfação corporal e a rejeição do próprio corpo. Além disso, vivenciaram experiências estigmatizantes que são refletidas de modo negativo nas suas relações sociais.

Palavras-chave Obesidade, Saúde do adolescente, Auto-imagem 


\section{Introdução}

A obesidade é resultante do aumento de tecido adiposo provocado pelo desequilíbrio entre ingestão alimentar excessiva e gasto energético diminuído. Para Fisberg, ${ }^{1}$ historicamente, a obesidade é provavelmente uma das mais antigas enfermidades do homem, pois segundo o autor, desenhos rupestres mostram o homem pré-histórico com aspectos de peso excessivo para a sua altura. No entanto, a partir da década de 60 , tudo se modifica; inicia-se a busca pelo corpo magro, atlético e formas definidas como objeto de consumo.

O mesmo autor ressalta que a obesidade está entre as situações nutricionais cujas estatísticas mais crescem, não só nas nações ricas, como também nos países em desenvolvimento. Assim, enquanto a moda atual investe a postura de "ser saudável" e adota a estética do manequim esquelético, milhares de pessoas sofrem com o peso excessivo, que juntamente com a obesidade são considerados problemas de saúde pública no Brasil.

Segundo Santos, 2 a obesidade vem tomando vultos alarmantes em todo o mundo, atingindo crianças, adolescentes e adultos de todos os estratos sociais. A incidência de adolescentes obesos brasileiros vem aumentando nos últimos anos no Brasil, principalmente nos grandes centros urbanos, independente da classe social a qual pertencem. De acordo com a OMS (Organização Mundial da Saúde), citada por Lauer e Clarke, 3 quinze milhões de crianças e jovens no Brasil pesam mais que o ideal, o que significa que mais de $15 \%$ da população infanto-juvenil apresenta peso corporal em excesso. Provavelmente, isso se deve a mudanças comportamentais que merecem especial atenção dos governantes, em razão do grave problema de saúde pública que representa.

Uma dieta saudável deve ser incentivada já na infância, evitando-se que crianças apresentem peso acima do normal, e quando apresentem, a reeducação alimentar é fundamental. Esse processo pode necessitar de suporte emocional ou social, através de psicoterapia individual, em grupo ou familiar.

A adolescência é uma etapa da vida que apresenta intensas transformações no processo de crescimento e desenvolvimento. Desta forma, a obesidade torna-se ainda mais problemática quando surge ou se agrava nessa etapa. De acordo com Muller, ${ }^{4}$ um dos momentos mais críticos para o aparecimento da obesidade é o início da adolescência.

Para Gomes 5 uma característica importante em pacientes obesos é a depreciação da própria imagem física, sentindo-se inseguros em relação aos outros e imaginando que estes os vêem com hostilidade e desprezo. Além disso, Allon 6 cita que adolescentes com sobrepeso freqüentemente referem ao peso como um fator agravante na interação social, sofrendo discriminações que interferem em seus relacionamentos sociais e afetivos.

Gomes $^{5}$ refere ainda que o adolescente apresenta constante preocupação com seu peso, visando um ideal de beleza imposto pelo corpo magro, e a não aceitação de seu corpo, o que o leva a sentir-se marginalizado na sociedade. Dessa maneira, adolescentes que se deparam com a obesidade têm muitos problemas em relação à aceitação de sua autoimagem e à valorização de seu próprio corpo.

Considerando todos esses aspectos, interessa-nos ter como objeto neste estudo a percepção dos adolescentes obesos com relação ao seu corpo e os reflexos da auto-imagem na vida social.

\section{Métodos}

O estudo é de cunho qualitativo fundamentado em Minayo.7 A opção por essa natureza de pesquisa baseia-se no fato de que ela se preocupa com um nível de realidade que não pode ser quantitativo, ou seja, a pesquisa qualitativa entende os meandros das relações sociais e afetivas, trabalhando com o universo de significados, crenças e valores, compreendendo e explicando essa dinâmica. Na enfermagem, a pesquisa qualitativa tem contribuído para o aperfeiçoamento da prática profissional.

O estudo foi desenvolvido em um programa de assistência ao obeso denominado Programa Multidisciplinar de Assistência ao Adolescente Obeso (PMAAO), promovido pela Escola de Enfermagem de Ribeirão Preto da Universidade de São Paulo. Esse programa atualmente é constituído por 30 adolescentes obesos de ambos os sexos, na faixa etária de 10 a 14 anos, oriundos das escolas de ensino fundamental da rede oficial de ensino de Ribeirão Preto; os adolescentes considerados obesos foram indicados para participarem desse programa.

O PMAAO é composto por uma equipe multidisciplinar, incluindo médicos, educadores físicos, psicólogos, nutricionistas e enfermeiros, que desenvolvem atividades junto aos adolescentes como: atividades motoras adequadas, educação nutricional e orientação psicológica. O programa espera alcançar determinados resultados, tais como: uma melhora da auto-estima; implementação de um estilo de vida saudável para toda a família; prevenção das comorbidades da obesidade; manutenção ou perda 
de peso, sem alterar o ganho estatural do adolescente; diminuição da circunferência abdominal.

Uma das atividades do Programa consiste em uma reunião mensal denominada Grupo de Vivência, da qual fazem parte 14 dos 30 adolescentes. Foi a partir desse Grupo de Vivência que percebemos que a auto-imagem estava muito presente em suas falas e que o sentimento de rejeitar o próprio corpo era manifestado constantemente.

Em relação a esse desenho amostral, observa Minayo, 7 que em pesquisa social de abordagem qualitativa, a composição da amostra não passa pela representatividade numérica e sim pela representatividade de complexidade do objeto em estudo. A partir do exposto, foram incluídos no estudo 14 adolescentes de ambos os sexos, sendo sete do sexo feminino e sete do sexo masculino, que se encontram entre 10 e 13 anos. O critério para a escolha da amostra baseou-se na condição de que esses adolescentes estivessem inscritos no PMAAO no ano de 2002 e, além disso, que freqüentassem o Grupo de Vivência proposto pelo programa. O estudo foi realizado no período de agosto a novembro de 2002.

Foi adotada como instrumento de coleta de dados, nessa investigação, a entrevista semi-estruturada. O roteiro com poucas questões é um guia, cuja finalidade, de acordo com Minayo, é aprofundar a comunicação. As entrevistas aconteceram individualmente durante uma das reuniões do grupo de vivência, ocorrida no mês de abril de 2002 , e basearam-se em incentivar os adolescentes obesos a expressarem como se sentiam na escola e/ou dentro de suas próprias famílias, ou seja, foram incentivados a contar como eram seus relacionamentos sociais, e como se sentiam diante deles.

Para completar as entrevistas, foi utilizado um espelho para realização dessa atividade, tendo sido solicitado ao adolescente que se posicionasse diante do espelho e respondesse às seguintes questões norteadoras: "Como você se vê diante do espelho?", "Qual é a parte do seu corpo que você mais gosta?" "Você acha que o seu corpo atrapalha na sua vida, em quê?"

Este instrumento foi escolhido, pois segundo Minayo, ${ }^{7}$ permite captar a informação desejada, além de possibilitar ao entrevistado a liberdade e espontaneidade para expressar-se sobre o tema. Através desse procedimento, pode-se obter dados objetivos e subjetivos acerca do assunto investigado. Para apreender melhor as informações desejadas, fizemos uso do gravador durante a entrevista e, por serem adolescentes os sujeitos dessa investigação, foi obtida, junto aos pais ou responsáveis dos mesmos, a autorização para participarem da entrevista através do Termo de Consentimento Livre e Esclarecido.

Os adolescentes foram entrevistados individualmente, com duração mínima de 15 minutos cada entrevista. Cada um dos participantes da pesquisa recebeu um símbolo diferenciado para preservar o seu anonimato. Assim, passamos a designá-los de A1, A-2, A-3, e assim por diante.

De acordo com a proposta de Gomes, ${ }^{8}$ para análise, interpretação e ordenação dos dados, realizaram-se os seguintes passos: transcrição das fitas, leituras exaustivas dos textos, classificação dos dados e estabelecimento de núcleos de sentido.

Para Gomes, 8 além de buscar respostas para as questões, com essa técnica pode-se investigar além das aparências, descobrindo o que está por trás dos conteúdos manifestados.

\section{Resultados e Discussão}

Foram identificadas as estruturas dos sujeitos sociais, das quais foram detectados os seguintes núcleos temáticos:

\section{Primeiro núcleo temático: a relação entre o corpo obeso e o espelho}

\section{A recusa}

Foi verificado o receio explícito de todos os adolescentes em ver sua imagem refletida no espelho. Inclusive uma parcela dos atores sociais (aproximadamente $25 \%$ ) recusou essa primeira etapa da atividade. Já os adolescentes que aceitaram olhar-se no espelho, fizeram-no rapidamente e, em seguida, olhando para o entrevistador responderam:

"Eu tenho vergonha de me olhar no espelho por causa do meu corpo...". (A-2)

"Não, eu não quero me olhar no espelho (disse chorando) porque sou feia". (A-7)

"Antes, quando eu era magro, eu gostava de me olhar no espelho, mas agora que eu sou gordo, eu não gosto! Assim... é porque eu fiquei feio, eu não gosto mais de mim, entendeu?". (A-1)

"Eu quero ser magra, aí sim não vou sentir vergonha de me olhar no espelho". (A-8)

O receio em ver a própria imagem corporal foi justificado pela vergonha que sentem de si, manifestando a rejeição pelo próprio corpo, bem como uma interferência direta da não aceitação do corpo com relação ao fator psico-emocional destes adolescentes. Alguns dos sujeitos analisados emocionaram- 
se diante do espelho, chegando ao choro durante a recusa de olharem sua própria imagem.

\section{Evitação}

Outro aspecto levantado pelos adolescentes é que quando se vêem no espelho, procuram fixar o olhar apenas em algumas partes do corpo e evitam olhar os lugares em que há um acúmulo exagerado de gordura, da mesma forma que preferem não se olhar no espelho para não se entristecer devido à insatisfação com o corpo. As falas abaixo demonstram o fato:

"Eu só olho no espelho do pescoço para cima".

"Eu olho no espelho só para passar batom". (A-7)

"Eu evito olhar para mim porque aí eu me acho feia, ai eu fico mais triste" (a menina chorou e recusou-se a olhar no espelho) (A-10)

"Quando eu coloco uma roupa, nem me olho no espelho para não ficar chateada, senão eu não vou querer nem sair de casa". (A-11)

\section{Preferência}

Do mesmo modo que os adolescentes obesos recusam em olhar seu corpo inteiro no espelho, também referem que as partes do corpo que mais gostam são aquelas em que o acúmulo de gordura é mínimo ou não se faz presente, como podemos verificar nestas falas:

"Só meu olho que é bonito, mas o resto não, ... não acho mais nada bonito em mim". (A-2)

"A única coisa que salva no meu corpo é a minha boca". (A-3)

"Gosto de minha boca, olho e do meu dedo, se não fosse a minha barriga e essa gordura, eu seria até bonito ...". (A-10)

\section{Segundo núcleo temático:} as influências na vida social

\section{Construção de identidade}

Nesta fase da vida, a construção da identidade pessoal inclui necessariamente a relação com o próprio corpo; e essa relação se faz através da representação mental que o jovem tem do seu corpo, ou seja, através de sua imagem corporal.

Para Tiba, 9 a identidade dos adolescentes se organiza através de identificações, inicialmente com os pais, professores e ídolos, mas depois com o "grupo de iguais", que constitui um importante modelo de identificação, pois é na turma que o adolescente compartilha e troca experiência. No entanto, quando se trata de adolescente obeso, esse se percebe diferente do "grupo de iguais", o que lhe ocasiona sentimentos de estranheza, negação do próprio corpo e impactos negativos na auto-estima e imagem corporal:

"Na escola, sinto que todos ficam reparando em mim, me acho diferente no meio da amigas, porque todas são magras e bonitas e eu gorda. Aí eles colocam apelidos e eu me acho mais feia ainda". (A-14)

"Fico revoltado comigo e com os outros. Comigo porque sou gordo e com os outros porque me xingam, falam apelidos que odeio. Eles me xingam de gordo". (A-6)

\section{Aparência física/mídia}

Segundo Santos, 10 a sociedade atualmente valoriza o modelo do corpo feminino esguio e esbelto, o que se torna objeto de desejo entre os jovens. Dessa forma, os adolescentes obesos não só valorizam como também, desejam ser/estar de acordo com os padrões de beleza estabelecidos pela mídia, para que então possam ter o sentimento de igualdade perante a sociedade. As falas abaixo comprovam esse fato:

"Quando eu me olho no espelho, tenho vontade de emagrecer ... tem brincadeiras de mau gosto na escola, os colegas ficam zombando da gente."(A-6)

"Quero emagrecer porque me sinto mal em todos os sentidos. Se eu emagrecer, eu não vou me sentir diferente dos outros, aí eu vou gostar de mim". (A-11)

\section{Transformações biológicas}

Em paralelo à obesidade, o adolescente enfrenta ainda, nesta fase da vida, as transformações biológicas que ocorrem no seu corpo. O jovem obeso, diante da turma (teoricamente não obesa), enfrenta dificuldades em integrar todas estas alterações corporais, dando-lhe freqüentes sentidos de estranheza pela própria imagem. Segundo Outeiral, ${ }^{11} \mathrm{o}$ corpo nesse momento passa a assumir um importante papel de rejeição por parte da turma; e o adolescente obeso começa a perceber que seu corpo não corresponde àquele idealizado para si e também para o grupo de iguais, e via de regra, é através da identificação e comparação com os outros adolescentes que ele começa a ter uma idéia concreta de seu corpo, passando a rejeitá-lo. Isso ficou claro nas falas:

"Na escola, sinto que todos ficam reparando em mim, me acho diferente no meio das amigas, porque todas são magras e bonitas e eu gorda. Ai eles colocam apelidos e eu me acho mais feia ainda". (A-14) 
"Meus amigos são magrinhos, aí eu fico olhando de cima em baixo eles, acho eles bonitos. Mas aí eu olho para mim, vejo que sou diferente e fico com raiva de mim, me sinto culpada por ser feia". (A-8)

De acordo com Hoover, 12 o corpo é freqüentemente a parte da pessoa que inicialmente é apresentada para o mundo em interações sociais, e o modo como nós pensamos que os outros vêem o nosso corpo é refletido em nosso auto-retrato e autoimagem.

\section{Vestimentas}

Outro aspecto destacado pelos jovens se refere à dificuldade em relação às roupas. A preocupação com as vestimentas que usam e que julgam não poder usar fica explícita em suas falas, principalmente em adolescentes do sexo feminino. As adolescentes manifestaram o desejo de poder usar as roupas da moda, mas recusam porque sentem vergonha de usá-las, referindo não ser bonito para elas que são obesas. Assim, os adolescentes obesos têm que optar por vestimentas de tamanho grande, que são as que servem para seu corpo:

"Quando eu saio com a minha mãe para comprar roupas e a vendedora me mostra muita roupa da moda que não me serve, fico com vergonha dela ... dá vontade de emagrecer para comprar o que eu gosto e não ficar usando estas roupas grandes e feias". (A-14)

"Não gosto de sair para comprar roupas porque nada me serve. Ai tenho que comprar as roupas com número maior, que não é da minha idade". (A-3)

\section{Preconceito}

O adolescente obeso muitas vezes vivencia experiências estigmatizantes ao sofrerem com brincadeiras e receberem apelidos pejorativos relacionados com seu excesso de peso, conforme podemos observar nestas falas:

"Ser gordo me atrapalha em tudo: dentro de casa porque meu irmão não é gordo, e quando brigamos, ele me xinga de apelidos como baleia e rolha de poço; e na escola porque meus colegas só me chamam por apelidos que eu não gosto. Ai eu me acho diferente deles, me sinto feio, não gosto do meu corpo ..." (A-12)

"Meu apelido na escola é toucinho, fico triste porque todos zombam de mim ..." (A-3)

"Na escola, sinto que todos ficam reparando em mim, me acho diferente no meio das amigas, porque todas são magras e bonitas e eu gorda. Ai eles colocam apelidos e eu me acho mais feia ainda". (A-14)
"Fico revoltado comigo e com os outros. Comigo porque sou gordo e com os outros porque me xingam, falam apelidos que odeio. Eles me xingam de gordo". (A-6)

"Eles colocam um monte de apelidos e eu não posso falar nada que eles apelam, começam a me chamar de gordo. Me sinto excluído, aí eu fico nervoso e não tenho mais vontade de brincar com eles porque só ficam me xingando ..." (A-7)

Num estudo realizado por Dechen, 13 a autora relata que os adolescentes obesos se sentem infelizes com sua gordura, pois recebem apelidos pejorativos dos colegas e se sentem rejeitados, o que ocasiona influências negativas da obesidade nos relacionamentos sociais dos adolescentes.

Tais fatos geraram sentimentos de conflito com a própria imagem corporal e baixa auto-estima. Foi constatado que os autores dessas brincadeiras e apelidos são outras crianças da escola, os amigos e os próprios irmãos. Além disso, observou-se que o "sentir-se diferente" diante da turma e as experiências estigmatizantes, devido aos apelidos pejorativos, ocasionam sentimentos de culpa por ser obeso e podem levar ao isolamento social com o objetivo de se proteger e suportar essas situações.

\section{Limitações}

Outro aspecto apontado como relevante no convívio social dos adolescentes obesos é a limitação na realização das atividades físicas, o que apareceu como mais um obstáculo real em conseqüência do excesso de peso, ocasionando prejuízos nos relacionamentos sociais, somados aos sentimentos de impotência e fracasso, conforme evidenciamos nas falas abaixo:

"Eu sempre perco quando brinco de pique-epega, porque não consigo correr como os outros, aí fico tão triste que não quero brincar mais". (A-1)

"Eu não consigo correr prá jogar bola, aí os colegas da escola começam a rir e me chamar por apelidos. Ai eles falam: "ah gordinho vai pro gol!" (A-5)

"Os colegas só me mandam pro gol, mas eu gosto mesmo é de jogar na linha. Mas aí eles falam que como eu sou gordo fica melhor no gol". (A-4)

"Quando tem educação fisica na escola pra mim é a pior parte, porque aí me colocam os apelidos chatos, me chamam de bola sete e falam: "você é goleiro porque tampa o gol inteiro". Ai eu fico nervoso e não tenho vontade de fazer educação física. A única coisa que eu não quero é que eles fiquem zombando de mim..." (A-2)

Verificou-se que o desempenho na atividade física é um determinante importante nas caracterís- 
ticas físicas do adolescente. Verificou-se também, que a limitação para realizar as atividades físicas como correr, por exemplo, é relatada com maior predominância pelos adolescentes do sexo masculino; enquanto que para os adolescentes do sexo feminino, a maior preocupação em relação às limitações está associada às roupas.

\section{Aspectos sociais}

Por outro lado, também foi constatada a dificuldade que os adolescentes obesos enfrentam no momento de fazer novos amigos e nas situações de paquera, como comprovam as falas que se seguem:

"Quando chego perto de alguém para fazer amizade, na maioria das vezes as pessoas me rejeitam e não querem ser meus amigos porque sou gordo, porque sou diferente deles". (A-3)

"Uma vez cheguei pra uma menina e falei que ela era linda e queria ficar com ela, ai ela falou que não gostava de gordos..." (A-7)

"Na escola fico mais sozinha, os outros ficam me zombando ... Só tenho uma amiga que não é gorda na escola". (A-11)

Os indivíduos obesos, algumas vezes, podem parecer alegres e despreocupados no convívio social, mas sofrem com o sentimento de inferioridade, insatisfação, carência afetiva e tendem a revelar profunda necessidades de serem amados e aceitos.

\section{Considerações finais}

$\mathrm{O}$ adolescente obeso apresenta sentimentos conflituosos com relação ao seu corpo, manifestando o receio explícito de ver a sua imagem diante de um espelho.

A maioria das falas citadas revela a insatisfação do adolescente obeso com seu corpo diante do estigma social, que dita o corpo magro como sendo o padrão de beleza. A interferência da mídia na imposição do corpo magro faz com que cada vez mais os adolescentes busquem para si esse estereótipo considerado como o da perfeição. Mas quando se trata de adolescentes obesos, essa imposição social ocasiona insatisfação corporal, sentimentos de angústia, vergonha e rejeição ao próprio corpo. $\mathrm{O}$ adolescente obeso passa a se perceber "diferente" perante a sociedade, afetando negativamente a sua auto-estima e auto-imagem corporal. Tal fato entra em consonância com o estudo de Dechen et al.,13 realizado com adolescentes obesos de ambos os sexos, na faixa etária de 11 a 13 anos, quanto à relação com o corpo e a influência desse na sua vida familiar, escolar e social.

O presente estudo mostrou que a relação do adolescente obeso com o corpo se faz de maneira conflituosa, carregada de sentimentos como angústia, vergonha e fracasso. Na escola, o adolescente experiencia momentos de sofrimento e dificuldades de fazer amigos e até na família ocorrem situações onde experiências estigmatizantes a respeito do peso ocorrem.

Constatou-se ainda a influência negativa do corpo obeso nos relacionamentos sociais dos adolescentes, o que foi comprovado pela dificuldade desses em relacionarem-se com os colegas de escola, assim como em fazer novas amizades. É notado o estigma social perante o excesso de peso, como foi constatado pelos apelidos pejorativos pelos quais os adolescentes obesos são freqüentemente chamados. Essas situações acabam por retirar do adolescente obeso a sua própria identidade, o que às vezes lhe dá a sensação de estranheza de si próprio. O adolescente obeso começa a perceber que seu corpo não corresponde ao idealizado para si e também para o grupo de iguais e, via de regra, é através da comparação com os outros adolescentes que ele começa a assumir um importante papel de insatisfação com o próprio corpo e rejeição por parte da turma.

Desta forma, o estudo alerta para a importância que deve ser dada na educação dos adolescentes sobre a questão do corpo e, principalmente para que os profissionais de saúde ou educação se esforcem na tentativa de influenciar positivamente sobre os sentimentos assumidos por esses adolescentes. 


\section{Referências}

1. Fisberg, M. Obesidade na infância e adolescência. Porto Alegre: Fundação Byk; 1995.

2. Santos GVB. Excesso de peso e seus fatores de risco em adolescentes da rede pública e privada de ensino do município de Ribeirão Preto [tese doutorado]. Ribeirão Preto: Escola de Enfermagem de Ribeirão Preto da Universidade de São Paulo; 2003.

3. Lauer RM, Clarke WR. Use of cholesterol measurements in childhood for the prediction of adult hypercholesterolemia: the muscatine study. JAMA 1990; 264: 3034-8.

4. Muller RCL. Obesidade na adolescência. Pediatr Mod 2001; 37: 45-8. [ed. especial].

5. Gomes RA. Análise de dados em pesquisa qualitativa. In: Minayo MCS, organizadora. Pesquisa social: teoria, método e criatividade. 4. ed. Petrópolis: Vozes; 1994. p. 67-80.

6. Allon N. Self-perceptions of stigma of overweight in relation to weight-patterns. Am J Clin Nutr 1979; 32: 470-80.

7. Minayo MCS. O desafio do conhecimento: pesquisa qualitativa em saúde. 6. ed. São Paulo: Rio de Janeiro: Abrasco; 1999

Recebido em 1 de outubro de 2003

Versão final apresentada em 26 de outubro de 2004

Aprovado em 28 de dezembro de 2004
8. Gomes RA Análise de dados em pesquisa qualitativa. In: Minayo MCS, organizadora. Pesquisa social: teoria, método e criatividade. 4. ed. Petrópolis: Vozes; 1994. p. 67-80.

9. Tiba I. Puberdade e adolescência: desenvolvimento biopsicossocial. São Paulo: Agora; 1986.

10. Santos MF. O sentido de existir de adolescentes que se percebem obesos: uma abordagem à luz de Merleau-Ponty [tese doutorado]. Ribeirão Preto: Escola de Enfermagem da Universidade de São Paulo; 1998.

11. Outeiral JO. Adolescer: estudo sobre adolescência. Porto Alegre: Artes Médicas; 1994.

12. Hoover ML. The self-image of overweight adolescent females: a review of literature. Matern Child Nur J 1984; 13: $125-37$

13. Dechen S, Cano MAT, Ferriani MGC, Ribeiro RPP. A obesidade na adolescência e seus reflexos na auto-imagem corporal. Rev Bras Sex Hum 2001; 12: 120-31. 